\title{
Detection of single nucleotide polymorphisms by minisequencing on a polypyrrole DNA chip designed for medical diagnosis
}

\author{
Alexandre Ho-Pun-Cheung ${ }^{1}$, Sylvie Choblet ${ }^{1}$, Thomas Colineau ${ }^{1}$, Hafid Abaibou ${ }^{2}$, \\ Daniela Zsoldos ${ }^{2}$, Karen Brengel-Pesce ${ }^{2}$, Jean Grenier ${ }^{1}$, Philippe Cleuziat ${ }^{2}$ and \\ Evelyne Lopez-Crapez ${ }^{1}$ \\ ${ }^{1}$ Cancer Research Center, Val d'Aurelle Cancer Institute, Montpellier, France and ${ }^{2}$ Apibio, Grenoble, France
}

\begin{abstract}
With the increasing availability of genetic information and its relationship to human diseases, there is a growing need in the medical diagnostic field for technologies that can proceed to the parallel genotyping of multiple markers. In this paper, we report the development of a new flexible microarray-based method that aims to be inexpensive, accurate, and adapted to routine analysis. The construction of the MICAM ${ }^{\mathbb{B}}$ (MICrosystem for Analysis in Medicine) DNA chip is based on the controlled electrosynthesis of a conducting polymer film bearing oligonucleotide probes on gold electrodes. First, accessible $3^{\prime} \mathrm{OH}-\mathrm{ends}$ of grafted probes are directly used to conduct single template-dependent nucleotide extension reactions with fluorescence-labeled chain terminators. Then, the fluorescence of incorporated dideoxynucleotides on controls and probes of interest are recorded to assess base calling. Here, we present the development of the methodology to assign the genotype of TP53 (tumor protein p53) codon 72 polymorphism and its application to analysis of genomic DNA from cell lines and from human colorectal samples. The genotyping results obtained by minisequencing on the polypyrrole DNA chip were $100 \%$ concordant with data obtained by polymerase chain reaction-restriction fragment length polymorphism and direct sequencing. Moreover, the developed probe array assay has been successfully applied to the detection of TP53 loss of heterozygosity.
\end{abstract}

Laboratory Investigation (2006) 86, 304-313. doi:10.1038/labinvest.3700387; published online 6 February 2006

Keywords: DNA chip; medical diagnosis; minisequencing; SNP detection; TP53 codon 72

The DNA of the human genome has numerous sequence variations, among which base substitutions are the most common. Depending on the location of the single-nucleotide variation, including single nucleotide polymorphisms (SNPs) and point mutations, different consequences may be brought about at the phenotypic level. SNPs in gene coding regions may alter the function or the structure of the encoded proteins and be associated with inherited monogenic disorders. On the other hand, mutations may be associated with complex multigenic pathologies such as diabetes, ${ }^{1}$ cardiovascular diseases, ${ }^{2}$ or cancer. ${ }^{3}$ Particularly in the field of oncology, mutations or polymorphisms in some cancer-related genes may be potential markers and

Correspondence: Dr E Lopez-Crapez, PhD, Centre de Recherche en Cancérologie, Centre Régional de Lutte contre le Cancer Val d'Aurelle-Paul Lamarque, Parc Euromédecine, 34298 Montpeller Cedex 5, France.

E-mail: ecrapez@valdorel.fnclcc.fr

Received 5 July 2005; revised and accepted 7 December 2005; published online 6 February 2006 contribute to the diagnosis of the pathology, determination of prognosis ${ }^{4}$ or management of the therapy. ${ }^{5}$ In this context, it is interesting for medical diagnostic purposes to proceed to the parallel genotyping of multiple SNPs/mutations.

In recent years, a multitude of genotyping methodologies for the detection of single nucleotide variations have been described. ${ }^{6-8}$ Classic genotyping technologies such as direct sequencing are complex, expensive, and time-consuming when large numbers of markers are required for a patient. To avoid these limitations, a promising approach would be to use arrays of oligonucleotides (DNA chips) on a solid support in miniaturized assays. The concept of oligonucleotide arrays was originally introduced for de novo nucleotide sequence-based hybridization. ${ }^{9}$ High-density oligonucleotide arrays such as variation detection arrays manufactured by Affymetrix have been developed to analyze single nucleotide variations using the principle of allelespecific oligonucleotide (ASO) hybridization. ${ }^{10} \mathrm{Hy}-$ bridization chips contain thousands of oligonucleotides, matching normal or mutant sequences. Under 
controlled hybridization conditions, probe-target heteroduplexes could be discriminated from perfectly matched probe-target duplexes, thus allowing the analysis of several polymorphisms or mutations. Nevertheless, this method presents limitations when multiple markers are simultaneously analyzed. ${ }^{11}$ Indeed, annealing efficiency and thermal stability depend strongly on both the nucleotide sequence composition and the stringency of the reaction conditions. It is then difficult to design a single set of experimental conditions that would provide optimal signal intensities and allow a simultaneous discrimination of a large number of sequence variants. To circumvent limitations of hybridization-based approaches, enzyme-mediated reactions have been developed.

Particularly, minisequencing is becoming the preferred allelic discrimination technology for the detection of known polymorphisms. Minisequencing is based on the extension of the $3^{\prime} \mathrm{OH}$-end of a probe by a single labeled dideoxynucleotide (ddNTP). Unlabeled PCR-amplified test DNA is hybridized to the probes, and extension by a DNA polymerase occurs only when the labeled ddNTP is complementary to the nucleotide of the target DNA adjacent to the $3^{\prime} \mathrm{OH}-e n d$ of the probe. This method is more accurate than ASO because the distinction between sequence variants depends on polymerasecatalyzed incorporation. The vast majority of array assays designed for genotyping by minisequencing such as tag arrays developed by Orchid Biosciences $^{12}$ and Affymetrix ${ }^{13}$ relies on a two-step process. It includes a liquid-phase enzymatic reaction followed by a detection step based on the capture of extension products on an array containing complementary hybridization tags. ${ }^{14}$ Recently, microarray-based minisequencing using solid-phase immobilized extension primers has been proposed for the analysis of the complete sequence of selected genes. ${ }^{11}$

Based on the availability of the human genome, ${ }^{15,16}$ high-density genotyping arrays have been designed to conduct large-scale linkage analysis or association studies, combining high-throughput with low data point cost. Unfortunately, such formats are not well adapted to medical diagnostic tests, where only a limited number of markers is needed.

Here, we describe a new flexible microarray-based method, especially designed for diagnostic purposes. This technology was designed to be inexpensive, accurate, and rapid, with a throughput adapted to routine analysis. The process is named MICAM ${ }^{\mathbb{R}}$ (MICrosystem for Analysis in Medicine). The construction of the MICAM ${ }^{\circledR}$ DNA chip, based on the fixation of $5^{\prime}$ pyrrole-labeled oligonucleotides on gold electrodes, has been described previously. ${ }^{17,18}$ The application of the MICAM ${ }^{\circledR}$ DNA chip to the detection of $K$-ras mutations in tumor samples by using ASO hybridization has been published recently. ${ }^{19}$ Here, we report the ability to perform minisequencing reactions on the developed polypyrrole DNA chip using the free $3^{\prime} \mathrm{OH}$-ends of grafted probes. The assay was applied to the TP53 (tumor protein p53) codon 72 SNP genotyping ${ }^{20}$ of DNA from cell lines and human colorectal samples. Recently, it has been demonstrated that this SNP could be an important determining factor for the prediction of treatment response and survival in clinical oncology. ${ }^{21}$

\section{Materials and methods}

\section{Cell Lines}

Breast and pancreatic carcinoma cell lines with a known TP53 codon 72 genotype, SK-BR-3 (homozygous, CGC (arginine (Arg))) and MIA PaCa-2 (homozygous, CCC (proline (Pro))), respectively, were purchased from the American Type Culture Collection and cultured under standard conditions.

\section{Colorectal Samples}

Surgical samples from colorectal carcinomas and the corresponding normal mucosa were resected from colorectal cancer patients (CRLC Val d'Aurelle, Montpellier, France) and stored in liquid nitrogen until extraction.

\section{DNA Extraction}

High-molecular-weight DNA from cell lines and patient colorectal samples was extracted using a classic phenol-chloroform protocol as described previously. ${ }^{22}$ All DNA samples were stored at $-80^{\circ} \mathrm{C}$. The determination of TP53 codon 72 polymorphism was achieved through direct sequencing or polymerase chain reaction-restriction fragment length polymorphism (PCR-RFLP) as described previously. ${ }^{23,24}$

\section{Preparation of Chips}

MICAM $^{\mathbb{R}}$ biochips are the result of microelectronic research and are made on a silicon support bearing 128 gold electrodes. ${ }^{17}$ Probes to be grafted (Table 1) are synthesized ex situ and purified. They are labeled at their $5^{\prime}$-end with a pyrrole residue using pyrrole-phosphoramidite building blocks and tailed with a poly $(\mathrm{T})_{10}$ spacer arm. The pyrrole group enables probe fixation on the gold electrodes using an electrocopolymerization process as described previously. ${ }^{18}$ Briefly, each of the 128 electrodes $(50 \mu \mathrm{m})$ was successively functionalized by electrochemical polymerization ( $1 \mathrm{~V} /$ satured calomel electrode) in an aqueous $0.1 \mathrm{M} \quad \mathrm{LiClO}_{4}$ solution containing $20 \mathrm{mM}$ pyrrole and $1 \mu \mathrm{M}$ of the pyrrole oligonucleotide to be addressed. 
Table 1 Characteristics of the grafted probes

\begin{tabular}{lll}
\hline Probe & $5^{\prime} \rightarrow 3^{\prime}$ sequence $^{\mathrm{a}}$ & Function \\
\hline P72S & GCTCCCAGAATGCCAGAGGCTGCTCCCC & TP53 codon 72 genotyping probe \\
PC & CCTACCGTACCCCCTCCCGT & Positive control \\
SEPA & bTTTAGCCTTACGCCTATGACGTCA & Extension control \\
SEPC & TTTAGCCTTAACGCCTCTGACGTCA & Extension control \\
SEPG & TTTAGCCTTAACGCCTGTGACGTCA & Extension control \\
SEPT & TTTAGCCTTAACGCCTTTGACGTCA & Extension control \\
DCbio & Bio-GCCTTGACGATACAGCTA & Detection control \\
\hline
\end{tabular}

Bio $=$ biotin.

${ }^{\mathrm{a}}$ Each probe was $5^{\prime}$-labeled with a pyrrole residue and a $\mathrm{d}(\mathrm{T})_{10}$ oligonucleotide linker.

${ }^{\mathrm{b}}$ For each SEP, the nucleotide in bold enabled template-independent extension with the complementary chain terminator.

\section{Target Preparation}

\section{PCR}

A region of $80 \mathrm{bp}$ containing the polymorphic site of interest was amplified from cell lines and patient DNA samples by PCR. Amplification was performed in a $\mathrm{T}_{\text {GRADIENT }}$ Thermocycler (Whatman-Biometra, Goettingen, Germany) with a final volume of $25 \mu$ l. The reaction mix contained $1 \times$ Qiagen PCR buffer, $200 \mu \mathrm{M}$ dNTP, $0.48 \mu \mathrm{M}$ of each forward $\left(5^{\prime}\right.$-GAA GACCCAGGTCCAGATGA- $\left.3^{\prime}\right)$ and reverse (5'GGTGTAGGAGCTGCTGGTG-3') primer, 2.5 U HotStarTaq ${ }^{\circledR}$ DNA Polymerase (Qiagen, Courtaboeuf, France), and $100 \mathrm{ng}$ of genomic DNA. The forward primer was $5^{\prime}$-phosphorylated to allow the enzymatic digestion of the sense strand. The enzyme was first activated during an initial denaturation step for $15 \mathrm{~min}$ at $95^{\circ} \mathrm{C}$, followed by 17 cycles at $94^{\circ} \mathrm{C}$ for $30 \mathrm{~s}, 66^{\circ} \mathrm{C}$ for $30 \mathrm{~s}$, and $72^{\circ} \mathrm{C}$ for $90 \mathrm{~s}$, with a touch down of $-0.5^{\circ} \mathrm{C}$ for the annealing temperature between each cycle. Then, 14 normal cycles were carried out at $94^{\circ} \mathrm{C}$ for $30 \mathrm{~s}, 58^{\circ} \mathrm{C}$ for $30 \mathrm{~s}$, and $72^{\circ} \mathrm{C}$ for $90 \mathrm{~s}$. A final extension step of $10 \mathrm{~min}$ at $72^{\circ} \mathrm{C}$ completed the reaction. Qualitative and quantitative analysis of PCR products was performed on a DNA1000 LabChip ${ }^{\circledR} \quad$ (Agilent Biotechnologies, Massy, France) and analyzed with the 2100 Bioanalyzer (Agilent Biotechnologies).

\section{Generation of ssDNA}

The primer excess was first eliminated during an exonuclease I (Amersham Biosciences, Orsay, France) digestion, then the $5^{\prime}$-phosphorylated sense strand was digested with lambda exonuclease (Amersham Biosciences). The reactions were driven at $37^{\circ} \mathrm{C}$ for 30 and $45 \mathrm{~min}$, respectively. After each digestion, the enzyme was inactivated at $80^{\circ} \mathrm{C}$ for $15 \mathrm{~min}$. The resulting purified antisense strand was kept at $4^{\circ} \mathrm{C}$ until subsequent reactions.

\section{Genotyping of TP53 Codon 72 on the Chip}

\section{Minisequencing reactions}

All minisequencing reactions were carried out in a hermetic reaction chamber placed in a temperature- controlled incubator. Before use, the chips were hydrated for $5 \mathrm{~min}$ with $20 \mu \mathrm{l}$ of ultrapure water DNase/RNase free (Sigma, Saint Quentin Fallavier, France). A prehybridization step was first conducted for $15 \mathrm{~min}$ at $45^{\circ} \mathrm{C}$ in a buffer containing $9 \mathrm{mM}$ phosphate, $2.5 \mathrm{mM} \mathrm{KCl}, 0.5 \mathrm{M} \mathrm{NaCl}, 0.05 \%$ Tween-20, $1 \times$ Denhardt, $10 \mu \mathrm{g} / \mathrm{ml}$ salmon sperm DNA, and $0.2 \mu \mathrm{M}$ polyA. During this time, the targets (1 pmol of the single-stranded PCR product and $500 \mathrm{fmol}$ of a positive control (PC) oligonucleotide) were heated at $95^{\circ} \mathrm{C}$ for $5 \mathrm{~min}$. The PCR product contained the TP53 codon 72 polymorphic site of interest, which was the template for the single extension of the P72S probe (Table 1). The PC target (PCT: 5'-GTAGTGACTTCATTANACGGGAGG GGGTACGGTAGGTACGGCTTGTTCTT-3'), with no homology with the human genome, was used to check the global quality of the various steps (hybridization, extension, and detection). Nucleotide $\mathbf{N}$ (A, C, G, or T) was the template for the single extension of the PC probe (Table 1). It was complementary to the biotinylated ddNTP used in the minisequencing reaction. Target hybridization was performed in a final volume of $20 \mu \mathrm{l}$ buffer (9 mM phosphate, $2.5 \mathrm{mM} \mathrm{KCl,} 0.5 \mathrm{M} \mathrm{NaCl}, 0.05 \%$ Tween-20, $1 \times$ Denhardt, $10 \mu \mathrm{g} / \mathrm{ml}$ salmon sperm DNA) for $1 \mathrm{~h}$ at $45^{\circ} \mathrm{C}$. The chips were then washed for 5 min with the washing buffer. Next, $20 \mu \mathrm{l}$ of the extension mix $(20 \mathrm{pmol}$ of the appropriate biotinlabeled ddNTP, $20 \mathrm{pmol}$ of each of the other unlabeled ddNTPs, and $8 \mathrm{U}$ of the Thermo Sequenase $^{\mathrm{TM}}$ (Amersham Biosciences) were added. The extension reaction was carried out at $45^{\circ} \mathrm{C}$ for $5 \mathrm{~min}$ and then at $60^{\circ} \mathrm{C}$ for $15 \mathrm{~min}$.

\section{Denaturation and detection}

To stop the reaction and melt the complexes formed by the target and the extended probe, the chip was washed successively with distilled water for $10 \mathrm{~s}$, then with $50 \%$ formamide at $60^{\circ} \mathrm{C}$ for $3 \mathrm{~min}$, and finally with distilled water for $10 \mathrm{~s}$. Biotinylated ddNTP incorporated into the probes was detected by incubation with a $50 \mathrm{mg} / \mathrm{l}$ solution of a streptavidinR-phycoerythrin conjugate (Invitrogen, Cergy Pontoise, France) in detection buffer for $10 \mathrm{~min}$ under 
dark conditions. Finally, the chips were washed for 10 min with the washing buffer.

Acquisition and analysis of the fluorescent signals Washing buffer was replaced by detection buffer and the chip was directly analyzed on the Apimager ${ }^{\circledR}$ (Apibio, Grenoble, France). ${ }^{25}$ Fluorescence levels were allocated to each probe with the analySIS ${ }^{\circledR}$ software (Soft Imaging System GmbH, Munster, Germany).

\section{Results}

\section{Accessibility of $3^{\prime} \mathrm{OH}-E n d s$ of Grafted Probes}

Before designing the minisequencing assay, the accessibility of $3^{\prime} \mathrm{OH}$-ends to the enzymatic reactions was checked using terminal deoxynucleotidyl transferase (TdT). TdT is a template-independent DNA polymerase that catalyzes the irreversible terminal repetitive addition of deoxyribonucleotides to the $3^{\prime} \mathrm{OH}$-end of DNA. During this step, probes were extended with one or more biotinylated dATP, which were further detected using the streptavidinR-phycoerythrin conjugate. Whatever the probes grafted onto the solid support (length, sequence, GC percent), a high specific signal was obtained. The mean fluorescence value for the extended probes was 13- to 27-fold higher than the nonspecific background value (nonaddressed gold electrodes or

\section{Assay Design}

A flow chart of the method is presented in Figure 1.

\section{Reaction controls}

In addition to the TP53 codon 72 genotyping probe (P72S probe), several control probes (Table 1) were designed and grafted onto the chip to verify the completion of the various minisequencing steps. First, a PC probe that evaluates the whole genotyping process (target hybridization, extension, and detection) was designed. For each biotinylated ddNTP incorporated, a PCT, whose central sequence was complementary to the PC probe, was designed. The four 50-base-long PCT differed from each other by only one base. Then, two other probes, used to test the extension and revelation steps, were added. Four self-elongating probes (SEP) ${ }^{26}$ were used to validate the extension step. The $3^{\prime} \mathrm{OH}$-ends of these probes are self-complementary and able to form dimers directly on the solid support. Each SEP, differing from one another by only one nucleotide, allowed the incorporation of a specific ddNTP in a template-independent extension reaction. A biotinylated probe (biotinylated detection control (DCbio)), corresponding to a sequence from exon 1 of the K-ras gene (outside potentially mutated

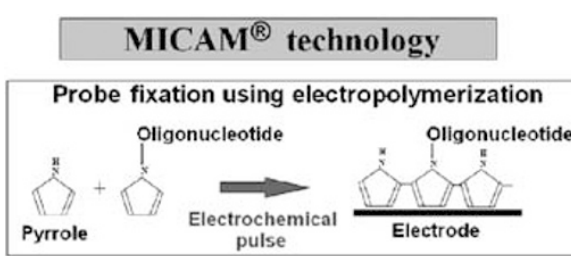

a

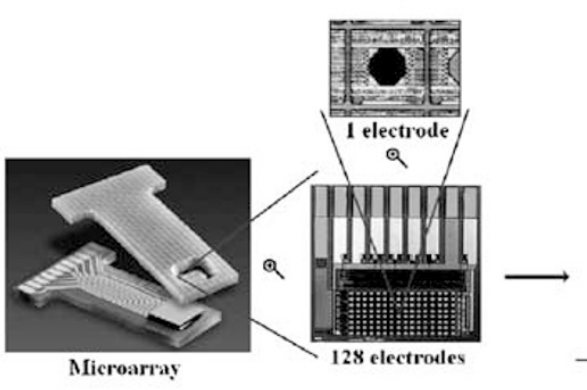

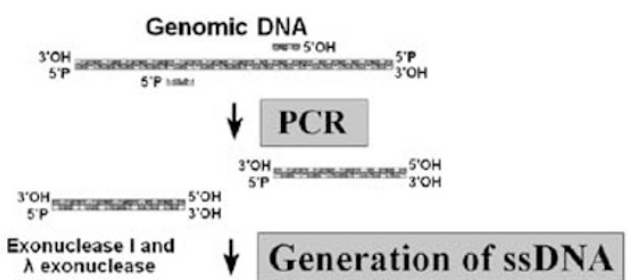

$\lambda$ exonuclease

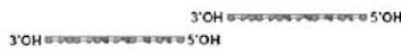

Single-stranded targets

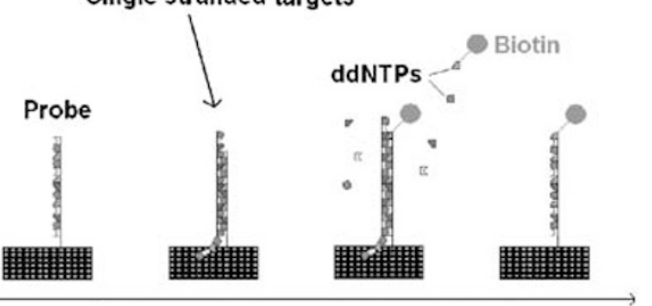

Minisequencing reaction

Image and data analysis
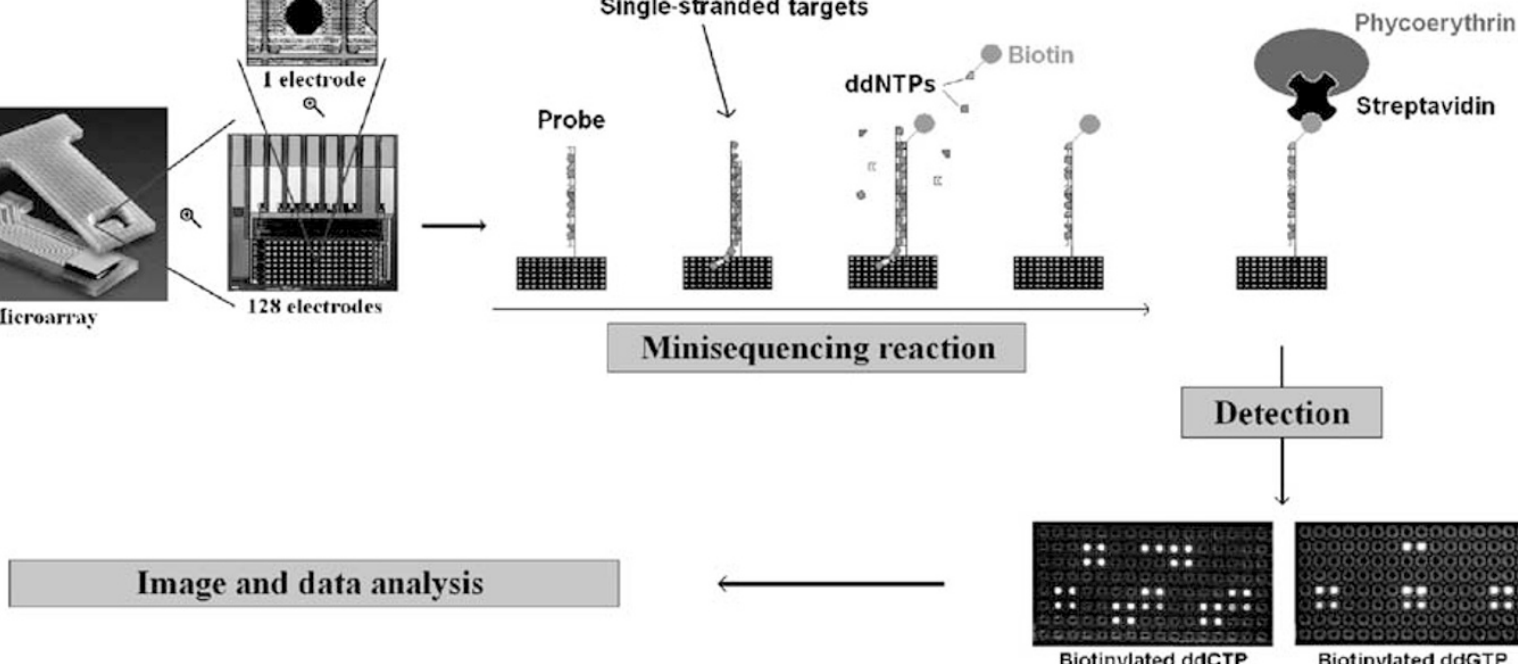

Detection

Figure 1 Method overview. 
codons 12 and 13), was then grafted onto the chip to verify the streptavidin-R-phycoerythrin detection step.

\section{Assay optimizations}

The key steps of the minisequencing reaction for SNP genotyping in the MICAM $^{\circledR}$ format were optimized in preliminary experiments, resulting in the protocol provided in the Materials and methods section. These optimizations covered probe and target design, reaction conditions, and reagent concentrations. First, we analyzed the impact of the pyrrole-labeled probe concentration during the grafting process on the hybridization signal. An increase from the standard $1 \mu \mathrm{M}$ concentration, corresponding to an estimated amount of $200 \mathrm{fmol} /$ $\mathrm{mm}^{2}$ of linked oligonucleotide, ${ }^{18}$ to $3 \mu \mathrm{M}$ combined with a 1:20 000 pyrrole-labeled probe/pyrrole monomer ratio resulted in a significant improvement of the hybridization signal (data not shown). Then, to increase the annealing efficiency, several probes were tested by hybridization with biotinylated targets. For minisequencing purposes, the last four bases at $3^{\prime} \mathrm{OH}$-end of the oligonucleotide probes must not be changed. Therefore, we focused on the length of both the poly(T) spacer arm and the probe in the direction of the $5^{\prime}$-end. Poly(T) tails from 0 to 15 base long were tested, and the best results were observed with a $(\mathrm{T})_{10}$ tail (data not shown). The optimal probe length was sequence dependent, and typically, selected probes demonstrating maximal hybridization signals were 20-30 bases long.

Regarding target design, we initially studied the incidence of the nonhybridized $3^{\prime} \mathrm{OH}$-end of the target on the hybridization signals. The role of this $3^{\prime}$-dangling end was assessed with a set of oligonucleotides and PCR products designed with or without a $3^{\prime}$-tail. Our results (data not shown) demonstrated that not only did the $3^{\prime}$-dangling end not constrain target annealing but it further stabilized the generated duplex. When the impact of target length was studied, we found an optimal hybridization for short products, less than 150-bplong. We decided to use 80-bp-long products for subsequent experiments. The use of single-stranded targets obtained by lambda exonuclease digestion of PCR products displaying a $5^{\prime}$-phosphate primer increased the specific signals by $50 \%$, whereas it decreased nonspecific signals by half. Finally, we extensively studied reaction conditions and reagent concentrations (buffer composition, step duration, and reaction temperatures).

\section{Probe specificity}

Probe design for a target-dependent solid-phase extension must fulfill several criteria. The principal requirement for the $\mathrm{PC}$ and the P72S probes is the absence of terminator incorporation when no target is used in the minisequencing reaction. Potential misincorporations during the extension step, caused by probe hairpins or dimer formations, were studied for each of the four ddNTPs. Under our optimized minisequencing conditions, no template-independent misincorporation occurred. In the absence of target, only the SEP were extended in the presence of the appropriate ddNTP, whereas the mean fluorescence values for the P72S and PC probes represented less than $1.5 \%$ of the specific SEP signals.

\section{Array Minisequencing Characterization}

\section{Technical quality}

Evaluation of the technical quality of our genotyping process was established by comparing the mean fluorescence signals of the PC probes with the background, that is, the nonaddressed gold electrodes. The absence of nonspecific fixation of biotinylated ddNTP or streptavidin-R-phycoerythrin was observed with low signals on nonaddressed electrodes. For 33 polypyrrole DNA chips reacted, each containing 25 nonaddressed electrodes, the mean background signal ( \pm s.d.) was $9 \pm 12$ fluorescence units (FU), whatever the biotinylated ddNTP used. Regarding the variability of minisequencing PCs, a total of 20 chips, each containing four PC probe electrodes, were reacted with biotinylated ddCTP or ddGTP terminators. The intrachip coefficients of variation were less than $8 \%$. Concerning the interchip analysis, the PC mean fluorescence signal ( \pm s.d.) was $1762 \pm 249 \mathrm{FU}$. The low signals on the nonaddressed electrodes and the high signal on the PC electrode resulted in a high signal/noise ratio.

\section{Genotype assignment}

Currently, base calling of a biallelic SNP requires two minisequencing reactions on two different polypyrrole DNA chips. To allow comparison between experiments and to prevent chip-to-chip variations, interpretation of results was based on relative data rather than absolute values. For this purpose, the PC probe was used for normalization. To validate the specific incorporation of one biotinylated ddNTP into the TP53 codon 72 genotyping probe, we calculated the identification (ID) percentage: $(\mathrm{P} 72 \mathrm{~S}$ signal/PC signal $) \times 100$, where the P72S signal represents the mean fluorescence value for the P72S probes.

\section{Specificity and sensitivity}

To evaluate the ability of the methodology to analyze genomic DNA, minisequencing reactions were performed on two cell lines with known TP53 codon 72 genotype: SK-BR-3 (homozygous, CGC (Arg)) and MIA PaCa-2 (homozygous, CCC (Pro)). After the generation of single-stranded antisense DNA from each cell line, minisequencing was directly carried out on the MICAM ${ }^{\mathbb{R}}$ chip. Both genotypes were unequivocally defined. Whereas high ID percentages were obtained when the correct ddNTP was incorporated into the P72S probes, the absence of 
specific incorporation was correlated with low ID percentages. For example, using a chip with a defined probe pattern (Figure 2a), when biotinylated ddCTP was used, the ID percentage was $96 \%$ for the homozygous CCC codon 72 cell line MIA PaCa-2 (Figure 2b) and 3\% for the homozygous CGC codon 72 SK-BR-3 cell line (Figure 2c). Then, to use this ID percentage as a genotyping tool, the threshold value, beyond which a ddNTP incorporation is considered as specific, was determined. For this purpose, we analyzed the minisequencing data (Table 2) obtained with homozygous TP53 codon 72 targets from both cell lines and human genomic DNA. Our experiments showed that whatever the biotinylated ddNTP used, the ID percentages for the nonspecific signals were always lower than $17 \%$. Finally, to assess the sensitivity of the approach developed, the ability to detect a minor fraction of a mutated allele within a large proportion of wild-type alleles was evaluated by mixing amplicons from the SK-BR-3 and MIA PaCa-2 cell lines. The results (Table 3) demonstrated that a sequence variant, corresponding to less than $25 \%$ of the total targets, could be unambiguously detected. Moreover, when only $10 \%$ of this allele is present in the reaction, the ID value $(23 \%)$ is superior to the maximal ID value reported for the nonspecific incorporation (17\%). Based on these two ID values, the threshold value was set at $20 \%$.

\section{Application to medical diagnosis}

Patient DNA samples extracted from surgically resected normal colorectal mucosa were analyzed by minisequencing on the MICAM ${ }^{\circledR}$ DNA chip, and the results were compared with data obtained by

PCR-RFLP and direct sequencing. Figure 3 illustrates the results obtained from three patients with three different genotypes. A total of 23 samples was

Table 2 Specificity of ddNTP incorporation into the TP53 codon 72 genotyping probe (P72S probe)

\begin{tabular}{clccc}
\hline \multirow{2}{*}{ Biotinylated ddNTP } & \multirow{2}{*}{$\begin{array}{c}\text { Number of } \\
\text { experiments }\end{array}$} & \multicolumn{2}{c}{$I D^{\mathrm{a}}(\%)$} \\
\cline { 3 - 5 } & & & Mean & Range \\
\hline \multirow{2}{*}{ ddGTP } & Specific signal $^{\mathrm{b}}$ & 28 & $80 \pm 14$ & $64-108$ \\
& Nonspecific signal $^{\mathrm{c}}$ & 16 & $6 \pm 5$ & $1-13$ \\
ddCTP & Specific signal $^{\mathrm{c}}$ & 16 & $112 \pm 20$ & $81-147$ \\
& Nonspecific signal $^{\mathrm{b}}$ & 32 & $8 \pm 5$ & $1-17$ \\
\hline
\end{tabular}

${ }^{\mathrm{a}}$ Identification percentage: (P72S signal/PC signal) $\times 100$.

${ }^{\mathrm{b}}$ Minisequencing reactions using homozygous CGC TP53 codon 72 targets.

${ }^{\mathrm{C}}$ Minisequencing reactions using homozygous CCC TP53 codon 72 targets.

Table 3 P72S probe extension with biotinylated ddCTP as a function of the proportion of amplicons from MIA PaCa-2 and SK-BR-3

\begin{tabular}{lcr}
\hline $\begin{array}{l}\text { Amplicon ratio } \\
\text { (MIA PaCa-2: }\end{array}$ & $\begin{array}{c}\text { Fluorescent-specific } \\
\text { signal }\end{array}$ & $I D^{\mathrm{a}, \mathrm{b}}(\%)$ \\
SK-BR-3) & units) & \\
\hline 100:0 & $2358 \pm 222$ & $96 \pm 9$ \\
$50: 50$ & $2064 \pm 313$ & $57 \pm 9$ \\
$25: 75$ & $514 \pm 90$ & $47 \pm 8$ \\
$10: 90$ & $331 \pm 34$ & $23 \pm 2$ \\
$0: 10$ & $49 \pm 29$ & $3 \pm 2$ \\
\hline
\end{tabular}

${ }^{\mathrm{a}}$ The results represent the mean values of eight experiments.

${ }^{\mathrm{b}}$ Identification percentage: (P72S signal/PC signal) $\times 100$.

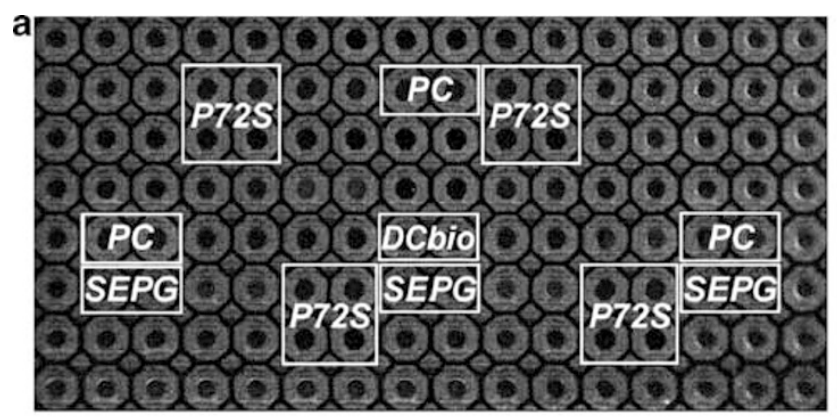

P72S: TP53 codon 72 genotyping probe

- PC: positive control probe

SEPG: extension control probe

DCbio: detection control probe
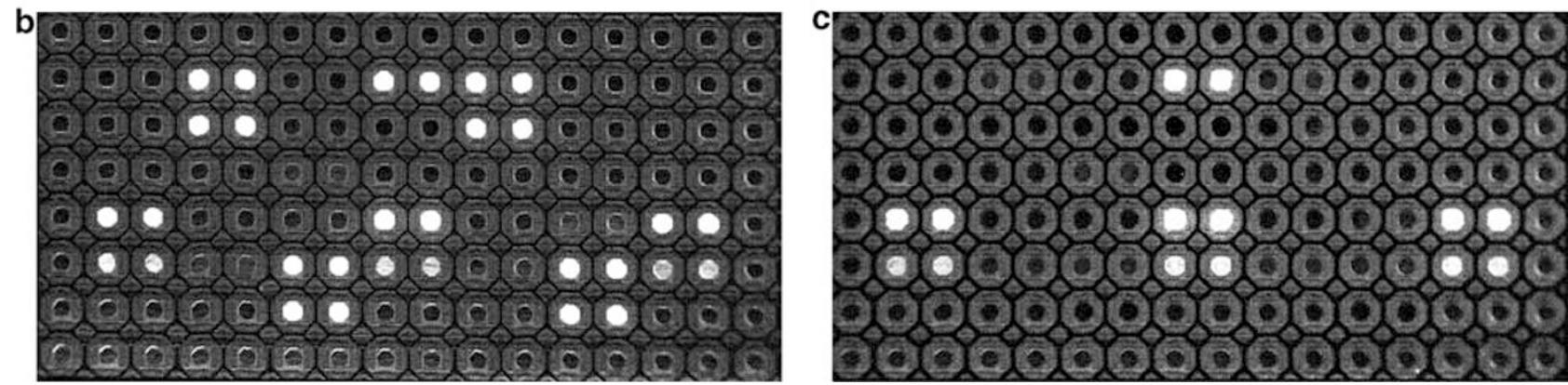

Figure 2 Cell line genotyping on the silicon chip. (a) Probe pattern. Minisequencing reactions were performed as described in Materials and methods on SK-BR-3 (b) and MIA PaCa-2 (c) cell lines by using biotinylated ddCTP as chain terminator. 


\begin{tabular}{|c|c|c|c|}
\hline $\begin{array}{l}\text { Patient } \\
\text { number }\end{array}$ & $\begin{array}{l}\text { Biotinylated } \\
\text { ddNTP }\end{array}$ & $I D(\%)$ & Genotype \\
\hline 00291 & $\begin{array}{l}\text { ddGTP } \\
\text { ddCTP }\end{array}$ & $\begin{array}{l}76 \\
11\end{array}$ & G/G \\
\hline 97B219 & $\begin{array}{l}\text { ddGTP } \\
\text { ddCTP }\end{array}$ & $\begin{array}{r}1 \\
128\end{array}$ & $\mathrm{C} / \mathrm{C}$ \\
\hline $95 B 390$ & $\begin{array}{l}\text { ddGTP } \\
\text { ddCTP }\end{array}$ & $\begin{array}{l}36 \\
77\end{array}$ & $\mathrm{G} / \mathrm{C}$ \\
\hline
\end{tabular}
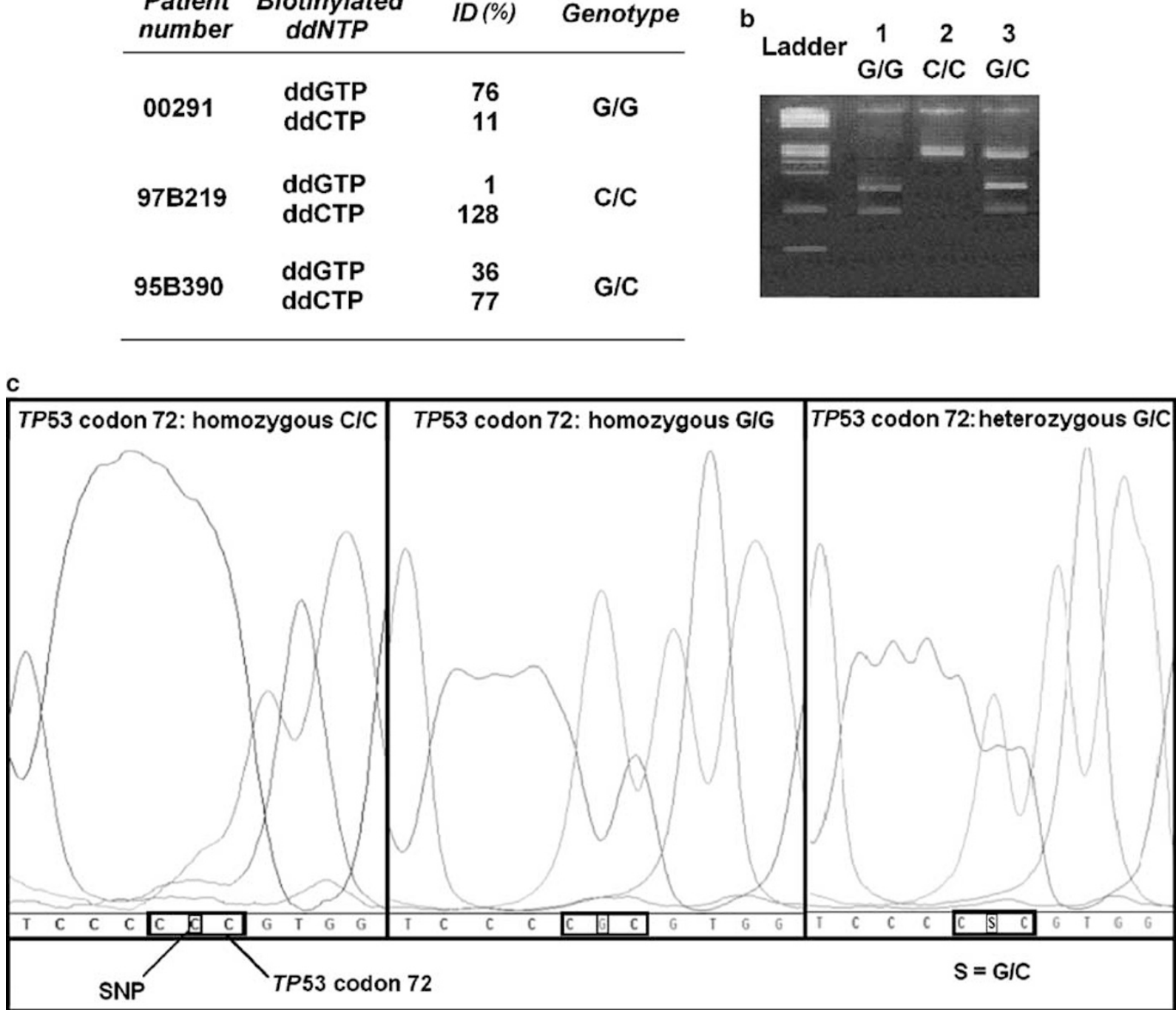

Figure 3 TP53 codon 72 genotyping by the MICAM ${ }^{\circledR}$ assay, PCR-RFLP, and direct sequencing. (a) TP53 codon 72 genotyping by minisequencing on MICAM ${ }^{\circledR}$. (b) TP53 codon 72 genotyping by PCR-RFLP. A 102 bp fragment including TP53 codon 72 was amplified and then digested by the restriction enzyme BstUI, which recognizes and cuts the restriction site CG $\mathbf{\nabla C G}$. The site was present in the homozygous G/G codon 72 samples (1). For homozygous C/C genotypes, the CCCG sequence was not cleaved (2). For heterozygous genotypes, three bands were visible (3). (c) Direct sequencing of TP53 exon 4 including codon 72 . PCR product sequencing was performed on the automatic DNA sequencer ALFexpress (Amersham Pharmacia Biotech) by using the thermosequenase fluorescentlabeled primer cycle sequencing method.

analyzed by the three approaches, and the genotypes scored by the polypyrrole DNA chip assay were $100 \%$ in agreement with conventional techniques. Moreover, because the codon 72 SNP may be used as an intragenic marker to detect loss of heterozygosity (LOH), we analyzed genotypes from paired tumor/ normal colorectal mucosa for various heterozygous patients. Typical results are reported in Table 4 for both an LOH and a non-LOH patient. DNA chip assays demonstrated that all ID scores for patient 95B390 were higher than $20 \%$. These values corresponded to a specific extension of the P72 probes by both the ddCTP and the ddGTP chain terminators in normal and tumor tissues. This patient had a heterozygous genotype with no LOH. In contrast, patient 92B439 showed a heterozygous genotype with an $\mathrm{LOH}$ in the corresponding tumor mucosa. This LOH reflects a TP53 allelic loss, previously determined on this patient by microsatellite analysis. ${ }^{23}$

\section{Discussion}

Single nucleotide polymorphisms represent a natural genetic variability with high frequency throughout the human genome. They can convey enhanced or reduced susceptibility towards specific inherited disorders by impairing or improving physiological function. They have been implicated in both monogenic and multigenic diseases. ${ }^{27} \mathrm{~A}$ high level of complexity is attained with diseases such as 
Table 4 LOH analysis on genomic DNA from colorectal cancer patients

\begin{tabular}{|c|c|c|c|c|c|}
\hline Patient number & Tissue & Biotinylated ddNTP & $I D^{\mathrm{a}}(\%)$ & Genotype & LOH analysis \\
\hline \multirow[t]{4}{*}{ 95B390 } & Normal & ddGTP & 36 & $\mathrm{G} / \mathrm{C}$ & No LOH \\
\hline & & ddCTP & 77 & & \\
\hline & Tumor & ddGTP & 26 & $\mathrm{G} / \mathrm{C}$ & \\
\hline & & ddCTP & 66 & & \\
\hline \multirow[t]{4}{*}{ 92B439 } & Normal & ddGTP & 44 & $\mathrm{G} / \mathrm{C}$ & $\mathrm{LOH}$ \\
\hline & & ddCTP & 112 & & \\
\hline & Tumor & ddGTP & 80 & G & \\
\hline & & ddCTP & 17 & & \\
\hline
\end{tabular}

$\mathrm{LOH}=$ loss of heterozygosity.

${ }^{\mathrm{a}}$ Identification percentage: (P72S signal/PC signal) $\times 100$.

cancer, ${ }^{28}$ where the disorder results from an accumulation of multiple alterations in a variety of genes regulating cellular growth, apoptosis, angiogenesis, and several other mechanisms. Another important group of genetic variations is those that alter the primary structure of a protein involved in drug metabolism and constitutes a target for pharmacogenomics. ${ }^{29}$ This approach represents a major advance in the medical field that would certainly help to refine the focus of treatments. This is especially important for oncology, where severe systemic toxicity and unpredictable efficacy are hallmarks of cancer therapies. ${ }^{30}$ In general, genes do not act in isolation, and response to treatment often relies on complex mechanisms. Therefore, polygenic analytical strategies for SNPs/mutations should be preferred over single gene studies. One can envision a future whereby comprehensive assessment of a set of genetic markers is conducted at the diagnostic stage. To be effective, this (r)evolution needs the development of diagnostic tools adapted to routine use.

To perform multiple clinically valuable tests for $\mathrm{SNP} /$ mutation detection, we propose a low-complexity (128 positions) silicon chip that fulfills the criteria of the clinical diagnostic market. This study reports the design of a new DNA chip based on electrocopolymerization of $5^{\prime}$-pyrrole-labeled oligonucleotides and minisequencing allelic discrimination for genotyping of the TP53 codon 72. Our assay allowed us to distinguish homozygous and heterozygous sequences unambiguously in both cell lines and human colorectal DNA samples. Moreover, application of the developed assay to paired nontumor/tumor samples allowed the analysis of TP53 allelic loss.

Traditionally, DNA chip manufacturing has been achieved either by 'on-chip' or 'off-chip' technologies. In the first case, microarrays of oligonucleotides are produced at very high density by combinatorial light-directed in situ synthesis on solid surfaces. ${ }^{31}$ Originally intended for ASO hybridization, these chips cannot be directly applied in DNA polymerase-assisted reactions since the oligonucleotide synthesis proceeds in the $3^{\prime} \rightarrow 5^{\prime}$ direction. To overcome this problem, $3^{\prime} \rightarrow 5^{\prime}$ complementary 'tag' oligonucleotides have been synthesized in situ and used as capturing probes for minisequencing products. ${ }^{14}$ To obtain DNA chips presenting at their surface free $3^{\prime}-\mathrm{OH}$ groups, various array in situ synthesis strategies have been devised based on the mask or maskless approach..$^{32-34}$ As in situ synthesis remains an attractive method for manufacturing high-complexity chips with hundreds of thousands of probes, an 'off-chip' technology is preferable for low-complexity array. In this case, individual oligonucleotides are synthesized prior to immobilization on the chip and may be used as substrates for enzymatic reactions. Enzyme-based methods for SNP/mutation detection are inherently more specific than those based on hybridization. ${ }^{11,35}$ Several approaches such as cleavage (eg the Invader $^{\mathrm{TM}}$ assay), ${ }^{36}$ ligation (eg oligonucleotide ligation assay $^{37}$ and ligation detection reaction ${ }^{38}$ ) or polymerase extension (eg pyrosequencing ${ }^{39}$ or minisequencing ${ }^{26,40}$ ) have been developed. Among these alternatives, minisequencing is becoming the most widely used method for SNP/mutation scoring because of its robustness, accuracy, simplicity, and flexibility. Moreover, the basic procedure has been adopted on several platforms. ${ }^{6}$ For solid-phasebased minisequencing reactions, several immobilization chemistries of oligonucleotides have been tested. ${ }^{41}$ In particular, for glass supports, it has been demonstrated that the efficiency of genotyping by minisequencing is largely dependent on the type of oligonucleotide attachment. ${ }^{41}$ In our solid-phase minisequencing assay, oligonucleotides are fixed on gold electrodes using pyrrole linkers in an electrochemical addressing process. ${ }^{17,18}$ Combined with a real-time quality control performed at each stage of the production, the developed array, where each electrode corresponds to a different unit of hybridization, is characterized by a homogeneous probe density at the electrode surface with free $3^{\prime}$ $\mathrm{OH}$ groups available for enzymatic reactions. Moreover, its microelectronic support structure yields highly predefined hybridization units compatible with easy readout. With regard to chip packaging, the array is easy to handle, and the microreaction 
chamber created is suitable for all steps of the genotyping process.

In this study, we have demonstrated that the $3^{\prime}$ $\mathrm{OH}$ ends of the grafted probes were accessible to various enzymes such as TdT and DNA polymerase. Minisequencing, like almost all allelic discrimination techniques, has its difficulties when attempting to type all polymorphisms. Nevertheless, the main steps of the minisequencing reaction have been extensively studied and certain general rules can be inferred. Our findings showed that longer probes improved the final signal. Optimal results were obtained with probes of interest ranging from 24 to 30 hybridizable bases. This length is similar to those previously reported in this type of array assay. ${ }^{42}$ For liquid-phase minisequencing, 24- to 30-base-long SNP primers should be used for experiments based on fluorescence polarization, whereas for mass spectroscopy assays, probes as short as 16 bases are preferred. In the absence of a cycling reaction, allowing the generation of large amounts of extension products, the quality of the target is primordial. We ensured optimal signals with short (less than 150 bases) single-stranded targets, presenting $3^{\prime}-$ and $5^{\prime}$-dangling ends.

Using the TP53 codon 72 polymorphism as a study model, minisequencing directly on the polypyrrole DNA chip was characterized by a high signal/noise ratio, and a high degree of reproducibility was obtained when various specific P72S probes were analyzed on the same chip. Nevertheless, despite these technical qualities, signal variations on extended probes were observed from chip to chip. Interchip fluctuations of minisequencing results are related to the individual chip electrocopolymerization process, and work on a wafer format is in progress to address several chips in parallel. In the future, batch production derived from a microelectronic standard will allow ondemand manufacturing of large volumes of biochips at competitive costs.

To allow comparison between experiments, the PC probes were used for normalization, and the ID percentage (probe of interest signal/PC signal) was calculated. Determination of methodology sensitivity showed that an amount of an allelic variant corresponding to less than $10 \%$ of the total DNA could be detected. This compares favorably with the sensitivity observed by using minisequencing and fluorescence detection on a glass support. ${ }^{42}$ For mutation genotyping, this detection threshold could be lowered. One option is to reduce the noise level by modifying the optics of the Apimager ${ }^{\circledR}$. Structured lighting by using liquid crystal matrix may restrict excitation light to the electrodes, thus decreasing the background signal. For base calling, analyses were carried out to determine a threshold, beyond which a ddNTP incorporation is considered as specific. Based on the data obtained from both nonspecific incorporation signals (Table 2) and sensitivity (Table 3), this cutoff value was set at
$20 \%$. One should note that all the ddNTPs did not have the same level of incorporation. This observation is not assay format dependent, since it has already been observed. ${ }^{43}$ Especially, in the assay developed, ddCTP was more efficiently incorporated than ddGTP, and these data were taken into account for result interpretation. This is illustrated for tumor tissues from patients 95B390 and 92B439 (Table 4), displaying two borderline ID values, 26 and $17 \%$, respectively. In the first case, there is no $\mathrm{LOH}$, because the ID percentage $(26 \%)$ is close to the value of $36 \%$ obtained for the normal tissue and two-fold greater than the highest nonspecific signal observed for this ddNTP (13\%). In the second case, the ID percentage $(17 \%)$ is less than the cutoff value of $20 \%$ and much lower than the value obtained for normal tissue $(112 \%)$. This led to the conclusion that there is no specific ddCTP incorporation in this case, meaning that there is an LOH. For LOH analysis, one could not exclude the presence of a small proportion of normal tissue, making result interpretation difficult in some cases.

Application of SNP scoring by the polypyrrole DNA chip assay to 23 human genomic DNA samples demonstrated a $100 \%$ correlation with conventional techniques such as direct sequencing and/or PCRRFLP. Finally, the number of minisequencing reactions required per sample on the developed diagnostic platform could be reduced from four to one by using ddNTPs labeled with four distinct dyes and a multicolor detection system.

In conclusion, the present results demonstrate that this flexible off-chip technology is well adapted for clinical diagnosis. It should be possible to increase significantly the number of polymorphic sites that can be typed per chip, without requiring additional work, by amplifying several separate targets during a multiplex PCR. Moreover, a quantitative application of this silicon device is conceivable because the number of grafted probes is fully controlled. Therefore, one could envisage both genotyping and gene expression analysis on the same support, with the same grafting technology, using the same analysis platform.

\section{Acknowledgements}

A Ho-Pun-Cheung, S Choblet, and T Colineau were supported by a grant from the Ligue Départementale contre le Cancer, Hérault, France. This study was supported by an SPRINTT grant from the Région Languedoc Roussillon. The quality of the technical work of J Noletti, N Beaufet, and AC Servanton was appreciated. We thank Dr B Fouqué (CEA/DSV, Grenoble, France) for helpful experiments at the beginning of the minisequencing project, $\mathrm{Dr} P$ Caillat (CEA/LETI, Grenoble, France) for the constant involvement in the 'MICAM' project, and Dr SL Salhi for critical comments and excellent presubmission editorial assistance. 


\section{References}

1 Van Tilburg J, van Haeften TW, Pearson P, et al. Defining the genetic contribution of type 2 diabetes mellitus. J Med Genet 2001;38:569-578.

2 Day IN, Wilson DI. Science, medicine, and the future: genetics and cardiovascular risk. BMJ 2001;323: 1409-1412.

3 Fearon ER, Vogelstein B. A genetic model for colorectal tumorigenesis. Cell 1990;61:759-767.

4 Andreyev HJ, Norman AR, Cunningham D, et al. Kirsten ras mutations in patients with colorectal cancer: the 'RASCAL II' study. Br J Cancer 2001;85: 692-696.

5 Kleyn PW, Vesell ES. Genetic variation as a guide to drug development. Science 1998;281:1820-1821.

6 Syvanen AC. Accessing genetic variation: genotyping single nucleotide polymorphisms. Nat Rev Genet 2001;2:930-942.

7 Kwok PY. Methods for genotyping single nucleotide polymorphisms. Annu Rev Genom Hum Genet 2001;2:235-258.

8 Gray IC, Campbell DA, Spurr NK. Accessing genetic variation: genotyping single nucleotide polymorphisms. Hum Mol Genet 2000;9:2403-2408.

9 Khrapko KR, Lysov Y, Khorlin AA, et al. A method for DNA sequencing by hybridization with oligonucleotide matrix. DNA Seq 1991;1:375-388.

10 Conner BJ, Reyes AA, Morin C, et al. Detection of sickle cell beta S-globin allele by hybridization with synthetic oligonucleotides. Proc Natl Acad Sci USA 1983;80:278-282.

11 Pastinen T, Kurg A, Metspalu A, et al. Minisequencing: a specific tool for DNA analysis and diagnostics on oligonucleotide arrays. Genome Res 1997;7:606-614.

12 http://www.orchid.com/.

$13 \mathrm{http}: / /$ www.affymetrix.com/.

14 Fan JB, Chen X, Halushka MK, et al. Parallel genotyping of human SNPs using generic high-density oligonucleotide tag arrays. Genome Res 2000;10:853-860.

15 Venter JC, Adams MD, Myers EW, et al. The sequence of the human genome. Science 2001;291:1304-1351.

16 Lander ES, Linton LM, Birren B, et al. Initial sequencing and analysis of the human genome. Nature 2001;409:860-921.

17 Caillat P, David D, Belleville M, et al. Biochips on CMOS: an active matrix address array for DNA analysis. Sens Actuator B 1999;60:154-162.

18 Livache $\mathrm{T}$, Roget $\mathrm{A}$, Dejean $\mathrm{E}$, et al. Preparation of a DNA matrix via an electrochemically directed copolymerization of pyrrole and oligonucleotides bearing a pyrrole group. Nucleic Acids Res 1994;11: 2915-2921.

19 Lopez-Crapez E, Livache T, Marchand J, et al. K-ras mutation detection by hybridization to a polypyrrole DNA chip. Clin Chem 2001;47:186-194.

20 Olivier M, Eeles R, Hollstein M, et al. The IARC TP53 Database: new online mutation analysis and recommendations to users. Hum Mutat 2002;19: 607-614.

21 Sullivan A, Syed N, Gasco M, et al. Polymorphism in wild-type TP53 modulates response to chemotherapy in vitro and in vivo. Oncogene 2004;23: 3328-3337.

22 Sambrook J, Fritsch EF, Maniatis T. Molecular Cloning: A Laboratory Manual. Clod Spring Harbor Laboratory Press: New York, 1989.
23 Thirion A, Rouanet P, Thezenas S, et al. Interest of investigating TP53 status in breast cancer by four different methods. Oncol Rep 2002;9:1167-1172.

24 Merlo GR, Cropp CS, Callahan R, et al. Detection of loss of heterozygosity in tumor DNA samples by PCR. Biotechniques 1991;11:166-168.

$25 \mathrm{http}: / /$ www.apibio.fr/.

26 Kurg A, Tonisson N, Georgiou I, et al. Arrayed primer extension: solid-phase four-color DNA resequencing and mutation detection technology. Genet Test 2000;4:1-7.

27 Gray IC, Campbell DA, Spurr NK. Single nucleotide polymorphisms as tools in human genetics. Hum Mol Genet 2000;9:2403-2408.

28 Fodde R. The APC gene in colorectal cancer. Eur J Cancer 2002;38:867-871.

29 Evans WE, Relling MV. Pharmacogenomics: translating functional genomics into rational therapeutics. Science 1999;286:487-491.

30 Marsh S, McLeod HL. Cancer pharmacogenetics. Br J Cancer 2004;90:8-11.

31 Fodor SP, Read JL, Pirrung MC, et al. Light-directed, spatially addressable parallel chemical synthesis. Science 1991;251:767-773.

32 Shchepinov MS, Case-Green SC, Southern EM. Steric factors influencing hybridisation of nucleic acids to oligonucleotide arrays. Nucleic Acids Res 1997;25:1155-1161.

33 Kwiatkowski M, Fredriksson S, Isaksson A, et al. Inversion of in situ synthesized oligonucleotides: improved reagents for hybridization and primer extension in DNA microarrays. Nucleic Acids Res 1999;27:4710-4714.

34 Albert TJ, Norton J, Ott M, et al. Light-directed $5^{\prime} \rightarrow 3^{\prime}$ synthesis of complex oligonucleotide microarrays. Nucleic Acids Res 2003;31:e35.

35 Halushka MK, Fan JB, Bentley K, et al. Patterns of single-nucleotide polymorphisms in candidate genes for blood-pressure homeostasis. Nat Genet 1999;22: 239-247.

36 Kwiatkowski RW, Lyamichev V, de Arruda M, et al. Clinical, genetic, and pharmacogenetic applications of the Invader assay. Mol Diagn 1999;4:353-364.

37 Landegren U, Kaiser R, Sanders J, et al. A ligasemediated gene detection technique. Science 1988;241: 1077-1080.

38 Barany F. Genetic disease detection and DNA amplification using cloned thermostable ligase. Proc Natl Acad Sci USA 1991;88:189-193.

39 Nordstrom T, Nourizad K, Ronaghi M, et al. Method enabling pyrosequencing on double-stranded DNA. Anal Biochem 2000;282:186-193.

40 Syvanen AC, Aalto-Setala K, Harju L, et al. A primerguided nucleotide incorporation assay in the genotyping of apolipoprotein E. Genomics 1990;8:684-692.

41 Lindroos K, Liljedahl U, Raitio M, et al. Minisequencing on oligonucleotide microarrays: comparison of immobilisation chemistries. Nucleic Acids Res 2001;29:e69.

42 Tonisson N, Zernant J, Kurg A, et al. Evaluating the arrayed primer extension resequencing assay of TP53 tumor suppressor gene. Proc Natl Acad Sci USA 2002;99:5503-5508.

43 Dubiley S, Kirillov E, Mirzabekov A. Polymorphism analysis and gene detection by minisequencing on an array of gel-immobilized primers. Nucleic Acids Res 1999;27:e19. 